\title{
The Impact of Online Teaching during the Coronavirus Pandemic on the Lives of
} Teachers and Parents

\section{Kashaf Aqeel Zaidi ${ }^{1}$ \\ Afreenish Gul ${ }^{2}$ \\ Farah Ahmad ${ }^{3}$}

'Lecturer, Community Health Sciences, Ziauddin University, Pakistan.

Email: kashafazaidi@gmail.com Tel:00923002839300

'Graduate, Ziauddin University, Pakistan.

Email:afreenish.gul@gmail.com Tel:00923412292027

${ }^{3}$ Professor, Community Health Sciences, Ziauddin University, Pakistan.

Email:farga24@gmail.com Tel:00923312440525

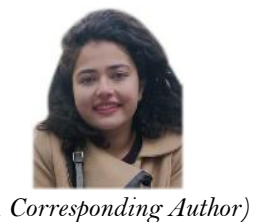

( Corresponding Author)

\section{Abstract}

To assess the degree of stress among teachers and parents of children taking online classes during the coronavirus pandemic. This was a cross-sectional study conducted in October 2020. An online questionnaire developed on Google Forms was circulated using convenience sampling technique with a sample size of 384 . The target population included teachers and parents of children taking online classes. An informed consent was taken prior to the survey. The Perceived Stress Scale was used to evaluate the stress related to online teaching. Chi square test was applied to identify associations and a p-value of less than 0.05 was taken as significant. Our sample included 414 participants with $\mathrm{n}=359(86.7 \%)$ females and $\mathrm{n}=55(13.3 \%)$ males. $\mathrm{N}=156(37.7 \%)$ participants were parents and $\mathrm{n}=258(62.3 \%)$ were teachers. Majority of the participants had moderate perceived stress with $\mathrm{n}=193(74.8 \%)$ teachers and $\mathrm{n}=127(81.4 \%)$ parents. Teachers felt more comfortable going back to school right now $\mathrm{n}=176(80.7 \%)$, whereas, only $\mathrm{n}=42(19.3 \%)$ parents felt comfortable sending their children back to school. ( $\mathrm{p}$-value $=0.000$ ) After the pandemic resolves, parents preferred classroom learning $n=111(44.6 \%)$ while $n=113(75.3 \%)$ teachers preferred a hybrid system with both online and classroom learning. ( $\mathrm{p}$-value $=0.001$ ). Majority of the teachers and parents were found to be in moderate perceived stress. An increase in working hours for teachers and increase in the required supervision time for parents were among the most common causes.

Keywords: Online learning, Coronavirus pandemic, Virtual classrooms, Stressful teaching, E-learning,

Citation | Kashaf Aqeel Zaidi; Afreenish Gul; Farah Ahmad (2020). The Impact of Online Teaching during the Coronavirus Pandemic on the Lives of Teachers and Parents. Asian Journal of Education and Training, 6(4): 658-663.

History:

Received: 30 October 2020

Revised: 12 November 2020

Accepted: 24 November 2020

Published: 9 December 2020

Licensed: This work is licensed under a Creative Commons

Attribution 3.0 License $($ (c) $)$ E

Publisher: Asian Online Journal Publishing Group
Acknowledgement: Authors would like to acknowledge Ziauddin University for granting us the permission to conduct this study.

Funding: This study received no specific financial support.

Competing Interests: The authors declare that they have no conflict of interests.

Transparency: The authors confirm that the manuscript is an honest, accurate, and transparent account of the study was reported; that no vital features of the study have been omitted; and that any discrepancies from the study as planned have been explained.

Ethical: This study follows all ethical practices during writing.

\section{Contents}

1. Introduction

2. Materials and Methods 


\section{Contribution of this paper to the literature}

This study contributes to existing literature by assessing the degree of stress among teachers and parents of children taking online classes during the coronavirus pandemic.

\section{Introduction}

The closure of educational institutions in an effort to maintain social distancing as a preventive and precautionary measure against COVID-19, have all changed the mode of teaching from a conventional standard system to a virtual and online framework (Moawad, 2020). Online learning systems are web-based software for distributing, tracking, and managing courses over the Internet (Keis, Grab, Schneider, \& Öchsner, 2017). Temporary solutions being devised for remote education range from online classroom tools like Google Classroom, to Zoom and podcasts by teachers. The primary objective is to dispense knowledge to students and enable them to learn at their own pace and convenience (Wadhwa \& Khatak, 2020). The interaction between facilitator, learner and study material along with emotional and social support are essential ingredients for effective learning (Bernard, E, Abrami, CA, \& RM, 2009).Therefore, educational units are struggling to find options to deal with this challenging situation (Dhawan, 2020). While parents are adjusting to this new scenario, during this time it's also important to help kids stay focused on learning and avoid overuse of games, social media, and videos (Pietra, 2020). This has understandably resulted in great stress on students. However, teachers and parents also appear to be worried by this paradigm shift in the educational system. Recommendations reflect that decorum can be maintained by thorough supervision of students, setting ground rules for online interaction, counseling and disciplinary actions (Stewart, 2008).

According to students and previous studies, the attention span during online learning is shorter than face to face sessions (Bradbury, 2016). Due to lack of immediate feedback, teachers were unable to assess students' understanding during online lecturing (Mukhtar, Javed, Arooj, \& Sethi, 2020). Some teachers also mentioned that during online study, students misbehaved and tried to access online resources during assessments (Mukhtar et al., 2020). Studies have shown a direct positive correlation between parent involvement and student success. Thus, various studies have shown that virtual schools work better when parents take an active role in their child's learning (Jain, 2020). A majority of parents found homeschooling "stressful and challenging" during the pandemic. Parents of children with Special Educational Needs (SEN) were most likely to experience difficulties in homeschooling (Bones, Bates, Finlay, Roulston, \& Taggart, 2020). Some parents complained that schools expected too much work to be completed while, for others, their children's school appeared less engaged after an initial period of support (Bones et al., 2020).

Many studies have been conducted to determine the stress amongst teachers or parents with school-based learning. However, since coronavirus pandemic is a novel concern, not much research has been conducted in this regard particularly related to parental stress. Therefore, our study aims to determine the stress associated with challenges related to the new normal, based on virtual learning, in teachers and parents alike. Moreover, we aim to determine the possible long-term consequences due to the change in teaching systems so measures can be taken to minimize distress and disadvantage for everyone including children, parents and teachers. Furthermore, our study will help establish the need for preparations to cope with future pandemics.

\section{Materials and Methods}

This was a cross-sectional study, data was collected in October 2020 in Karachi, Pakistan. The sample size calculated was $n=384$ which was calculated based on a proportion of $50 \%$, bound of error was $5 \%$ and confidence level was taken as $95 \%$. An online questionnaire developed on Google Forms was circulated via school and parent focus groups, social media, various websites and social forums through convenience sampling technique. The target population included teachers and parents of children taking online classes. An informed consent was taken at the beginning of the survey and those who did not wish to continue were allowed to leave the survey. The questionnaire was developed through literature review and researches conducted on similar topics. $(12,13)$ Demographic profile variables included age, gender, and level of education. A validated questionnaire, the Perceived Stress Scale (PSS) was used to evaluate the stress related to online teaching. (14) The questions acquired opinions of parents and teachers along with the challenges faced by them during the pandemic. Data entry was done on Microsoft Excel via Google Forms which was imported to SPSS Version 20. Descriptive analysis for numerical data was done through mean and standard deviation and for categorical data through frequencies and percentages. Chi square test was applied to identify associations between demographic factors and opinion about online teaching. A p-value of less than 0.05 was taken as significant. Institutional ethical approval was taken from the institute prior to the initiation of the study.

\section{Results}

Our sample included $n=414$ participants inclusive of teachers taking online classes and parents of children taking online classes during the coronavirus pandemic with $\mathrm{n}=359(86.7 \%)$ females and $\mathrm{n}=55(13.3 \%)$ males. The mean age of participants was $38 \pm 9$ years with $16 \pm 2.5$ years of education. Amongst all the participants, $n=156$ $(37.7 \%)$ were parents and $n=258(62.3 \%)$ were teachers.

Table 1 reflects on the major associations with the degree of stress among teachers and parents due to the online teaching system. Out of the teachers feeling stressed, $n=156(37.7 \%)$ said they felt it occasionally, $n=55$ $(13.3 \%)$ felt stressed all the time and $n=36(8.7 \%)$ only felt stressed around the time of assessments. While recording lectures, taking online lectures or facing technical issues were also listed as stressful times. A significant proportion of the people stated that they felt stressed initially but overtime they have become comfortable so the stress has reduced. 


\begin{tabular}{|c|c|c|c|c|c|c|c|c|}
\hline \multicolumn{9}{|l|}{ Perceived Stress Scale } \\
\hline \multicolumn{2}{|l|}{ Risk factors for stress } & \multicolumn{2}{|c|}{ Low stress } & \multicolumn{2}{|c|}{ Moderate stress } & \multicolumn{2}{|c|}{ High stress } & \multirow[t]{2}{*}{ P-value } \\
\hline & & $\mathrm{n}$ & $\%$ & $\mathrm{~N}$ & $\%$ & $\mathrm{n}$ & $\%$ & \\
\hline \multirow{2}{*}{ Parent or teacher? } & Teachers & 50 & 19.4 & 193 & 74.8 & 15 & 5.8 & \multirow{2}{*}{0.03} \\
\hline & Parents & 16 & 10.3 & 127 & 81.4 & 13 & 8.3 & \\
\hline \multirow{2}{*}{ Gender } & Females & 51 & 14.2 & 282 & 78.6 & 26 & 7.2 & \multirow{2}{*}{0.03} \\
\hline & Males & 15 & 27.3 & 38 & 69.1 & $\mathrm{O} 2$ & 3.6 & \\
\hline \multirow{4}{*}{ Marital status } & Married & 53 & 17.2 & 239 & 77.6 & 16 & 5.2 & \multirow{4}{*}{0.06} \\
\hline & Separated/Divorced & 01 & 5.0 & 16 & 80.0 & O3 & 15.0 & \\
\hline & Single & 10 & 13.5 & 58 & 78.4 & 06 & 8.1 & \\
\hline & Widowed & $\mathrm{O} 2$ & 16.7 & 07 & 58.3 & O3 & 25.0 & \\
\hline \multirow{2}{*}{$\begin{array}{l}\text { Do you feel stressed due } \\
\text { to online classes? }\end{array}$} & Yes & 19 & 7.9 & 197 & 82.4 & 23 & 9.6 & \multirow{2}{*}{0.000} \\
\hline & No & 47 & 27.0 & 122 & 70.1 & 05 & 2.9 & \\
\hline \multirow{2}{*}{$\begin{array}{l}\text { Did you find it difficult to } \\
\text { adapt to technology? }\end{array}$} & Yes & 12 & 8.3 & 125 & 86.8 & 07 & 4.9 & \multirow{2}{*}{0.003} \\
\hline & No & 54 & 20.0 & 195 & 72.2 & 21 & 7.8 & \\
\hline \multirow{5}{*}{$\begin{array}{l}\text { Grade } \\
\text { teaching/studying? }\end{array}$} & Primary & 31 & 14.7 & 166 & 78.7 & 14 & 6.6 & \multirow{5}{*}{0.01} \\
\hline & Secondary & 06 & 7.1 & 70 & 83.3 & 08 & 9.5 & \\
\hline & High school & 15 & 19.5 & 58 & 75.3 & 04 & 5.2 & \\
\hline & Undergraduate & 14 & 35.9 & 23 & 59.0 & $\mathrm{O} 2$ & 5.1 & \\
\hline & Postgraduate & OO & 0.0 & O3 & 100 & OO & 0.0 & \\
\hline
\end{tabular}

Table-2. Parental and teacher perspective.

\begin{tabular}{|c|c|c|c|c|c|c|}
\hline \multicolumn{7}{|l|}{ Parental and teacher perspective } \\
\hline \multirow{2}{*}{\multicolumn{2}{|c|}{ Risk factors for stress }} & \multicolumn{2}{|c|}{ Parents } & \multicolumn{2}{|c|}{ Teachers } & \multirow[t]{2}{*}{ P-value } \\
\hline & & n & $\%$ & $\mathbf{n}$ & $\%$ & \\
\hline \multirow{2}{*}{ Gender } & Females & 139 & 38.7 & 220 & 61.3 & \multirow{2}{*}{0.266} \\
\hline & Males & 17 & 30.9 & 38 & 69.1 & \\
\hline \multirow{2}{*}{$\begin{array}{l}\text { Did you find it difficult to adapt to } \\
\text { technology? }\end{array}$} & Yes & 55 & 38.2 & 89 & 61.8 & \multirow{2}{*}{0.875} \\
\hline & No & 101 & 37.4 & 169 & 62.6 & \\
\hline \multirow{2}{*}{$\begin{array}{l}\text { Do you experience disruption due to } \\
\text { internet connectivity issues? }\end{array}$} & Yes & 107 & 31.4 & 234 & 68.6 & \multirow{2}{*}{0.000} \\
\hline & No & 49 & 67.1 & 24 & 32.9 & \\
\hline \multirow{2}{*}{$\begin{array}{l}\text { Do you experience disruption due to } \\
\text { electricity issues? }\end{array}$} & Yes & 82 & 28.3 & 208 & 71.7 & \multirow[t]{2}{*}{0.000} \\
\hline & No & 74 & 59.7 & 50 & 40.3 & \\
\hline \multirow{3}{*}{$\begin{array}{l}\text { Do you feel comfortable going/sending } \\
\text { your child to school right now? }\end{array}$} & Yes & 42 & 19.3 & 176 & 80.7 & \multirow{3}{*}{0.000} \\
\hline & No & 74 & 47.4 & 82 & 52.6 & \\
\hline & Not sure & 39 & 100 & $\mathrm{O}$ & 0.0 & \\
\hline \multirow{3}{*}{$\begin{array}{l}\text { Which form of learning would you prefer } \\
\text { after the pandemic? }\end{array}$} & $\begin{array}{l}\text { Classroom } \\
\text { learning }\end{array}$ & 111 & 44.6 & 138 & 55.4 & \multirow{3}{*}{0.001} \\
\hline & $\begin{array}{l}\text { Online and } \\
\text { classroom }\end{array}$ & 37 & 24.7 & 113 & 75.3 & \\
\hline & No preference & $\mathrm{O} 4$ & 57.1 & 03 & 42.9 & \\
\hline \multirow{2}{*}{ Do you feel stressed about online classes? } & Yes & 94 & 39.3 & 145 & 60.7 & \multirow{2}{*}{0.295} \\
\hline & No & 61 & 35.1 & 113 & 64.9 & \\
\hline \multirow{2}{*}{$\begin{array}{l}\text { Has social media played a role in your } \\
\text { perception of the coronavirus? }\end{array}$} & Yes & 121 & 36.3 & 212 & 63.7 & \multirow{2}{*}{0.348} \\
\hline & No & 35 & 43.2 & 46 & 56.7 & \\
\hline \multirow{2}{*}{$\begin{array}{l}\text { Do you think this change in teaching } \\
\text { system will have any long-term effects? }\end{array}$} & Yes & 99 & 36.8 & 170 & 63.2 & \multirow[b]{2}{*}{0.400} \\
\hline & No & 56 & 38.9 & 88 & 61.1 & \\
\hline \multirow{3}{*}{$\begin{array}{l}\text { How important is it to prepare for future } \\
\text { pandemics? }\end{array}$} & $\begin{array}{l}\text { Extremely } \\
\text { important }\end{array}$ & 115 & 38.0 & 188 & 62.0 & \multirow{3}{*}{0.313} \\
\hline & Important & 35 & 34.7 & 66 & 65.3 & \\
\hline & Not important & O5 & 62.5 & 03 & 37.5 & \\
\hline
\end{tabular}

Table 2 lists the major differences between parental and teachers' perspective regarding online teaching system during the pandemic. Amongst those experiencing internet connectivity issues, $n=120(29 \%)$ suffered once a week, $\mathrm{n}=85(20.5 \%)$ once in two weeks and $\mathrm{n}=60(14.5 \%)$ once a month whereas, $\mathrm{n}=38(9.2 \%)$ were having internet issues every day. A significant proportion of the participants $n=104(25.1 \%)$ were experiencing electricity disruptions once a week, $n=69(16.7 \%)$ once in two weeks, $n=51(12.3 \%)$ once a month while $n=45(10.9 \%)$ were experiencing problems every day. However, most of the participants mentioned having alternate arrangements during absence of electricity including generators and others.

Most of the parents $n=72(46.2 \%)$ had one school going child, $n=63(40.4 \%)$ had two school going children while $n=17(10.9 \%)$ and $n=4(2.6 \%)$ had three or four, respectively. No significant association was found between the number of school-going children and degree of stress $(\mathrm{p}$-value=0.132). Majority of the parents $\mathrm{n}=108(69.2 \%)$ had children attending primary school, $n=27(17.3 \%)$ were in secondary school and $n=20(12.8 \%)$ were in high school. Most of the parents $\mathrm{n}=85$ (54.5\%) were paying between PKR 20,000 to PKR 60,000 as the combined monthly school fee of their children, whereas, $n=44(28.2 \%)$ were paying PKR 20,000 or less. A small proportion $\mathrm{n}=20$ (12.8\%) were paying between PKR 60,000 and PKR 100,000 while only (4.5\%) were paying more than PKR 100,000. There was no significant association between the combined monthly school fee of children and the degree of stress among parents (p-value=0.551). Majority of the parents $n=129(82.7 \%)$ did not have financial difficulty in arranging devices for their children while $\mathrm{n}=27(17.3 \%)$ did. As per the government regulations, $\mathrm{n}=90(57.7 \%)$ received fee waivers from school while $n=66(42.3 \%)$ did not receive them. Amongst those who received waivers, 
$78.9 \%$ received $20 \%$ fee reduction and a significant association was found as there was a lower degree of stress in parents who received waivers. $(p-v a l u e=0.03)$.

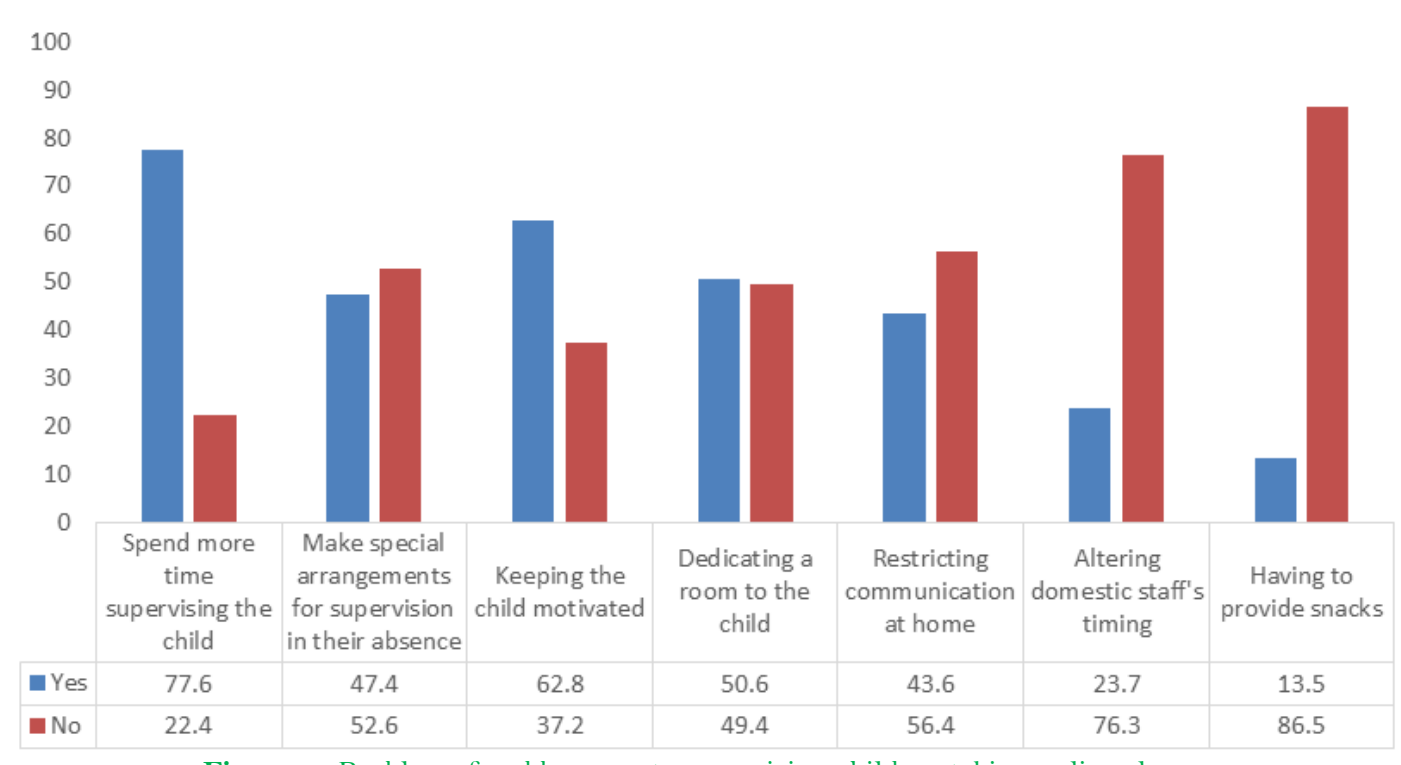

Figure-1. Problems faced by parents supervising children taking online classes.

Figure 1 highlights the common problems faced by parents. Out of those who had to make alternate arrangements for supervision, $39.7 \%$ had to do so every day while others had to do so on a less frequent basis. Others had to reduce work timings or avoid going for the same reason.

Majority of the teachers $n=165(64 \%)$ believed online classroom environment was productive for learning only to some extent, $n=62(24 \%)$ thought it was very productive and $n=31(12 \%)$ believed it was not. Only $n=59$ $(22.9 \%)$ of the teachers had difficulty maintaining discipline during online classes. Majority $\mathrm{n}=202(78.3 \%)$ felt their work hours had increased and $n=201(77.9 \%)$ stated that their overall workload has increased. A significant impact on personal or family life was experienced by $n=176(68.2 \%)$. Moreover, majority of the teachers $n=209(81 \%)$ did not experience salary deductions during the pandemic. Among those $n=49(19 \%)$ who did experience deductions, $7 \%$ had $20 \%$ deduction of their salary while others had a wide range of deduction, leave encashment or cancelled increments for the year 2020.

Participants identified some common stress relief practices including praying $\mathrm{n}=257$ (62.6\%), drinking tea/coffee $n=136(33.1 \%)$, listening to music $n=85$ (20.8\%), exercise $n=82(20 \%)$, talking to someone $n=76(18.4 \%)$, smoking $\mathrm{n}=24(5.8 \%)$, taking a sleeping pill $\mathrm{n}=16(3.9 \%)$, sleeping naturally $\mathrm{n}=13(3.1 \%)$, spending time with friends or family $n=13(3.1 \%)$, watching television and movies $n=7(1.8 \%)$. Swimming, reading, taking a break from work or school were among the other stress relievers.

\section{Discussion}

The findings from this study suggest that there is an association between moderate perceived stress among parents and teachers subject to online teaching systems in the setting of the COVID-19 pandemic. Parents showed higher levels of perceived stress in comparison to teachers. This could be attributed to the challenges of maintaining a conducive learning environment at home for the children, such as eliminating distractions or tailoring a timetable. A significant majority stated that they had to supervise their children more than in the past and make special arrangements to ensure productivity. It is crucial to identify the degree of stress as greater COVID-19 related stressors and high anxiety and depressive symptoms are associated with higher parental perceived stress (Brown, Doom, Lechuga-Peña, Watamura, \& Koppels, 2020). Out of those feeling stressed, a majority experienced it occasionally. Quarantines have negative psychological effects, often deemed as marginal, including symptoms related to anxiety, depression, acute stress, and even manifestations of post-traumatic stress disorder (Taylor, Agho, Stevens, \& Raphael, 2008).

A statistically significant percentage of participants did not experience difficulty adapting to the demands of digital learning methods or arranging devices to aid this. This is possibly because the participants of this online survey were comfortable with the use of electronic devices. However, a great majority did report disruption due to poor internet connectivity, especially teachers. Perhaps this is because of the professional demands of ideally teaching without interruption. COVID-19 has brought about a situation where Internet access seems to have become necessary for survival (De', Pandey, \& Pal, 2020). There are two core assumptions that underlie online teaching. First, that everybody — students and faculty - has digital access, computers and internet connections, capable of withstanding heavy bandwidth calls (De' et al., 2020). And second, that all faculty members are trained to teach online (Waqar, 2020). According to teachers, the lack of reliable, high-speed internet can make an already overwhelming job of pivoting to online instruction even more stressful (Will, 2020). Additionally, a great number of participants, mostly teachers, also encountered problems due to an unsteady electric supply; with most stating that it affected them at least once a week. This could also have served as a barrier for effective communication and a possible stressor.

Most participants believed that online learning was productive only to some extent and most teachers having high perceived stress preferred returning to classroom learning or the development of a hybrid educational system which incorporated elements of classroom and online learning both. It is reasonable to suggest that this may be because teachers have greater autonomy in a physical classroom and receive immediate feedback from students without the limitations of connectivity. A vast majority indicated that their work hours had increased in order to meet the demands of the new teaching methods in place, as had the overall workload. This could also be contributing to the advocacy of classroom learning. On average primary teachers seem to be most affected, 
spending more hours on each of the activities than secondary and tertiary teachers (Beng, Wardle, \& Collie, 2020). Institutional support barriers such as the budget for purchasing advanced technologies, a lack of training, a lack of technical support and a lack of clarity and direction were also reported (Joshi, Vinay, \& Bhaskar, 2020). To meet the needs of 21 st century learners in online, face-to-face, and hybrid contexts, teachers should better leverage technological resources (Schleicher, 2012). There is also a significant impact on their personal and family life. (Williamson, Eynon, \& Potter, 2020)

Parents, on the other hand, did not feel comfortable sending their children back to school yet in the setting of the pandemic, possibly due to the risk of contracting the virus. Most parents who participated in this study were married with one child of school going age achieving primary education. It is plausible that this may be contributing to their reservations since younger children require strict monitoring and it is difficult to adhere to SOPs such as maintaining distance in playgrounds, frequently washing hands or wearing masks at all times. However, most parents voted in favor of classroom only learning after the resolution of the pandemic. This could perhaps be because of the additional time and supervision needed for home learning. Chung, Lanier, and Wong (2020) It appears that teachers have become well acquainted with online classroom modalities and feel more comfortable than parents. A majority believes that the change in teaching system will have long term effects including, but not limited to, classroom dynamics, attention span, on paper assessments and overall student attendance.

In an attempt to relieve stress, most participants resorted to prayers. In times of crisis, humans have a tendency to turn to religion for comfort and explanation (Bentzen, 2020). Most participants who reported feeling stressed actually had moderate perceived stress. Additionally, a significant percentage of those who did not feel stressed were also suffering from moderate levels of stress. This can be explained by the relatively high baseline levels of stress due to the uncertainty and general concern for health in such unprecedented times. Both parents and teachers stated the need to be better prepared for any future pandemics as it affected them in various ways. Perhaps better strategies and infrastructural support can help improve mental health outcomes. A majority mentioned the role of social media in contributing to their perception of the pandemic. This may also have led to heightened emotions and alarm, contributing to the overall stress experienced by the participants.

Our study had some limitations as due to the pandemic probability sampling technique could not be used and we had to rely on surveys with convenience sampling technique. The strength of this research is that it provides quantitative data on this topic, which is rare, particularly in our country. This data will help us to make future recommendations for post-pandemic learning and in preparing for future pandemics. We recommend further studies especially qualitative research required to address the depth of this issue with respect to all stakeholders including teachers, parents and students.

\section{Conclusion}

Majority of the teachers and parents of children taking online classes during the coronavirus pandemic were found to be in moderate perceived stress. Various causes were identified including an increase in working hours for teachers and increase in the required supervision time for parents. As the mental and emotional well-being of caregivers and teachers is of vital importance to maintain a healthy and productive learning environment for the children, early recognition and timely intervention can help improve the long-term outcome for them. In an already traumatizing experience of a pandemic, stress related to education can have significant long-term effects on students, parents and teachers alike. Therefore, it is crucial to conduct more research in this regard and introduce interventional strategies on mass scale to prevent any major repercussions.

\section{References}

Beng, H., Wardle, L., \& Collie, P. (2020). Teachers' wellbeing and workload during Covid-19 lockdown: Durham University.

Bentzen, J. (2020). In Crisis, we pray: Religiosity and the COVID-19 Pandemic (May 2020). CEPR Discussion Paper No. DP14824. Available at SSRN: https://ssrn.com/abstract $=3615587$.

Bernard, R. M., E, B., Abrami, P. C., CA, W., \& RM, T. (2009). A meta-analysis of three types of interaction treatments in distance education. Review of Educational Research, 79(3), 1243-1289.

Bones, U., Bates, J., Finlay, J., Roulston, S., \& Taggart, S. (2020). Experiences of supporting children's home learning during COVID-19: Ulster University. Eani.org.uk.

Bradbury, N. A. (2016). Attention span during lectures: 8 seconds, 10 minutes, or more? Adv Physiol Educ, 40, 509-513.Available at: 10.1152 /advan.00109.2016.

Brown, S. M., Doom, J. R., Lechuga-Peña, S., Watamura, S. E., \& Koppels, T. (2020). Stress and parenting during the global COVID-19 pandemic. Child Abuse \& Neglect, 104699.

Chung, S. K. G., Lanier, P., \& Wong, P. (2020). Mediating effects of parental stress on harsh parenting and parent-child relationship during coronavirus (COVID-19) Pandemic in Singapore. Journal of Family Violence.

De', R., Pandey, N., \& Pal, A. (2020). Impact of digital surge during Covid-19 Pandemic: A viewpoint on research and practice. International Journal of Information Management, 55, 102171.Available at: 10.1016/j.ijinfomgt.2020.102171.

Dhawan, S. (2020). Online learning: A panacea in the time of COVID-19 crisis. Journal of Educational Technology Systems, 49(1), 5-22.Available at: https://doi.org/10.1177/0047239520934018.

Jain, M. (2020). Parents and their response to online learning in time of COVID-19 [Internet]. BW Education.

Joshi, A., Vinay, M., \& Bhaskar, P. (2020). Impact of coronavirus pandemic on the Indian education sector: Perspectives of teachers on online teaching and assessments. Interactive Technology and Smart Education.

Keis, O., Grab, C., Schneider, A., \& Öchsner, W. (2017). Online or face-to-face instruction? A qualitative study on the electrocardiogram course at the University of Ulm to examine why students choose a particular format. BMC Medical Education, 17(1), 194.Available at: $10.1186 / \mathrm{s} 12909-017-1053-6$.

Moawad, R. A. (2020). Online learning during the COVID-19 pandemic and academic stress in University students. Romanian Journal for Multidimensional Education, $12(1 \mathrm{Sup} 2), 100-107$

Mukhtar, K., Javed, K., Arooj, M., \& Sethi, A. (2020). Advantages, limitations and recommendations for online learning during COVID-19 pandemic era. Pakistan Journal of Medical Sciences, 36(COVID19-S4).

Pietra, H. (2020). COVID-19 and at-home learning [Internet]. Children and Screens.

Schleicher, A. (2012). Preparing teachers and developing school leaders for the 21 st century: Lessons from around the world: OECD Publishing.

Stewart, D. (2008). Classroom management in the online environment. Journal of Online Learning and Teaching, 4(3), 371-374.

Taylor, M. R., Agho, K. E., Stevens, G. J., \& Raphael, B. (2008). Factors influencing psychological distress during a disease epidemic: Data from Australia's first outbreak of equine influenza. BMC Public Health, 8(1), 347.Available at: 10.1186/1471-2458-8-347. 
Wadhwa, N., \& Khatak, S. (2020). Online versus offline mode of education -Is India ready to meet the challenges of online education in lockdown? Journal of the Social Sciences, 48(3), 404-413.

Waqar, K. (2020). Going online: Lessons from the classroom. Dawn News. Karachi, Pakistan.

Will, M. (2020). Teachers without Internet work in parking lots, empty school buildings during COVID-19. Education Week, 39(32), 17.

Williamson, B., Eynon, R., \& Potter, J. (2020). Pandemic politics, pedagogies and practices: Digital technologies and distance education during the coronavirus emergency. Learning, Media and Technology, 45(2), 107-114. 